DOI: $10.12731 / 2658-4034-2021-12-5-128-144$ УДК 616.89

\title{
ОСОБЕННОСТИ \\ ЭМОЦИОНАЛЬНО-ВОЛЕВЫХ И КОГНИТИВНЫХ НАРУШЕНИЙ У ЮНОШЕЙ ПРИЗЫВНОГО ВОЗРАСТА, ОБРАТИВШИХСЯ В ПСИХОНЕВРОЛОГИЧЕСКИЙ ДИСПАНСЕР
}

\section{Г.В. Сенченко, А.Ю. Сенченко, В.В. Саури, П.М. Серебренникова}

Расстройства личности занимают лидирующие места по распространенности среди призывного контингента и военнослужащиих. В структуре пограничных психических расстройств, послуживших причиной освобождения от срочной службы в армии и комиссованных из ее рядов, эмоционально-волевые расстройство личности занимает ведущее место.

Цель. Изучение структуры и особенностей эмочиональноволевых и когнитивных нарушений у юношей призывного возраста, обратившихся в психоневрологический диспансер в период с 2012 nо 2021 годы.

Материалы и методы исследования. Проведён анализ данных патопсихологического тестирование 146 юношей призывного возраста, обратившихся в психоневрологический диспансер в период с 2012 по 2021 гг. В исследовании использованы методы патопсихологической диагностики. Оиенивались следующие показатели: поведение во время исследования, внимание, память, операциональная сторона мышления, интеллект, особенности личностной и эмочионально-волевой сферьл.

Результаты. У 9,6士2,4\% обследованных призывников патология выявлена не была. Наибольшее число выявленной патологии отнесено в группу акиентуация-транзиторное психотическое расстройство (39,4士4,3\%). Второе место занимает группа «шизофрения и шизотипические расстройства» (20,4士3,5\%). На третьем месте 
расположилась патология, объединенная в группу «умственная отсталость» (16,7士3,2\%). Четвертое и пятое место разделили "расстройство личности» (11,4士2,8\%) и когнитивные нарушения $(9,1 \pm 2,5 \%)$. Реже всего выставлялся диагноз «тревожно-депрес-

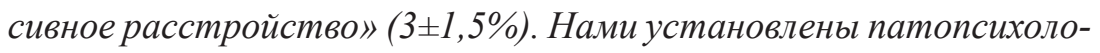
гические симптомы характерные для каждой из групп, выявленной патологии.

Выводы. 1. Проведенный анализ обрашцений юномей призывного возраста в психоневрологический диспансер за 10 лет установил разнонаправленность динамики выявленной у них патологии. 2. Ведущими группами выявленной патологии у обследованных призывников являются: акцентуация-транзиторное психотическое расстройство (39,4 4,3\%); шизофрения и шизотипические расстройства $(20,4 \pm 3,5 \%)$; умственная отсталость $(16,7 \pm 3,2 \%)$. 3. Для каждой из выявленных групп патологий характерны свои особенности. Для группы акиентуация-транзиторное психотическое расстройство характерны: снижение отсроченной памяти; неустойчивость активного внимания и истощаемость психических прочессов; снижение способности к абстрагированию; тендениия к снижению проиесса обобщения; нанесение самоповреждений. Для группь шизофрения - неустойчивость активного внимания, легкое снижение смысловой памяти; нарушение ассоциативного и мотивацчонного компонентов мыиления; нарушение целенаправленности мыслительных операций; своеобразие, субъективность, бессодержательность и нелогичность суждений и т.д. Для призывников с установленным диагнозом «умственная отсталость» было характерно: крайне низкий уровень общих сведений и знаний; скудный словарный запас, узкий кругозор; темп работоспособности неравномерный, с тендениией к снижению к кониу исследования; активное внимание с трудностями концентрации и переключения, истощаемость психических процессов и т.д.

Область применения результатов. Результаты исследования могут быть использованы в работе патопсихологов и призывных 
комиссий военкоматов, а также при проведении занятий со студентами специальности «клиническая психология».

Ключевые слова: психчческое здоровье; юноши призывного возраста; патопсихологическое исследование; акцентуации характера; иизофрения; умственная отсталость; расстройство личности

\title{
FEATURES \\ OF EMOTIONAL-VOLITIONAL AND COGNITIVE DISORDERS IN YOUNG MEN OF MILITARY AGE WHO APPLIED TO A NEUROPSYCHIATRIC DISPENSARY
}

\author{
G.V. Senchenko, A.Yu. Senchenko, V.V. Sauri, \\ P.M. Serebrennikova
}

Personality disorders occupy leading positions in terms of prevalence among the conscription contingent and military personnel. Emotional-volitional personality disorder occupies a leading place in the structure of borderline mental disorders that caused the release from military service in the army and those who were commissioned from its ranks.

Purpose. To study the structure and features of emotional-volitional and cognitive disorders in young men of military age who applied to a neuropsychiatric dispensary in the period from 2012 to 2021.

Materials and methods of research. The analysis of the data of pathopsychological testing of 146 young men of military age who applied to a neuropsychiatric dispensary in the period from 2012 to 2021 was carried out. The methods of pathopsychological diagnostics were used in the study. The following indicators were evaluated: behavior during the study, attention, memory, the operational side of thinking, intelligence, features of the personal and emotional-volitional sphere.

Results. Pathology was not detected in $9.6 \pm 2.4 \%$ of the examined conscripts. The largest number of detected pathology is attributed to the ac-

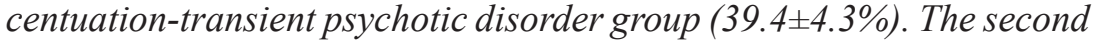
place is taken by the group "schizophrenia and schizotypal disorders" $-20.4 \pm 3.5 \%)$. Pathology, combined in the group "mental retardation" 
$(16.7 \pm 3.2 \%)$, took the third place. The fourth and fifth places were divided by "personality disorder" (11.4 $2.8 \%)$ and cognitive impairment $(9.1 \pm 2.5 \%)$. The least frequent diagnosis was "anxiety-depressive dis-

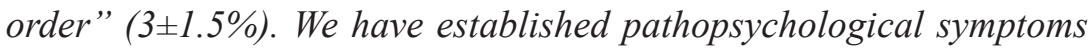
characteristic of each of the groups identified pathology.

Conclusions. 1. The analysis of the occurrence of mental pathology in young men of military age who were diagnosed in a neuropsychiatric dispensary for 10 years established the multidirectional dynamics of the pathology revealed in them. 2. The leading groups of revealed pathology in the examined conscripts are: accentuation-transient psychotic disor-

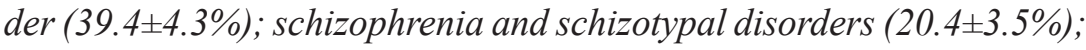

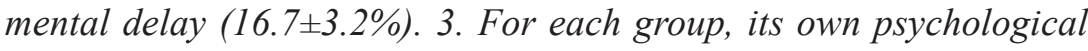
characteristics were identified, which must be taken into account not only when determining the suitability for the army, but also determining the conditions of service in the army.

Practical implications. The results of the study can be used in the work of pathopsychologists and draft commissions of military enlistment offices, as well as during classes with students of the specialty "clinical psychology».

Keywords: mental health; young men of military age; pathopsychological research; character accentuation; schizophrenia; mental retardation; personality disorders

\section{Актуальность}

Состояние здоровья молодёжи - это важнейший индикатор благополучия государства, позволяющий прогнозировать и формировать основные тенденции государственной политики не только в сфере здравоохранения, но и в вопросах национальной безопасности страны. В настоящее время отмечаются высокие показатели пограничной патологии, поведенческих нарушений, стресс-обусловленных расстройств, различных видов зависимостей [1]. Расстройства личности занимают лидирующие места по распространенности среди призывного контингента и военнослужащих $[2,3]$. В структуре пограничных психических расстройств, послуживших причиной освобождения от срочной службы в армии и комиссованных из ее 
рядов, эмоционально-волевые расстройство личности занимает ведущее место [3, 4, 5, 6].

Необходимость военно-психиатрического обследования определяется высоким уровнем психической заболеваемости у лиц призывного возраста, широким распространением среди молодежи злоупотребления наркотических и алкогольных веществ, низкими социально-психологическими характеристиками подрастающего поколения, а также повышением требований к состоянию психического и психологического здоровья военнослужащих $[1,7]$.

Современные требования к службе в армии обусловлены не только возможностью службы в условиях отличных от «домашних», но и возможностью участия в боевых действиях, а также использования современного высокотехнологичного оборудования. Это требует более пристального внимания к изучению состояния психического здоровья и изучения структуры выявленной психиатрической патологии молодых людей призывного возраста $[1,8,9,10,11]$.

Цель исследования: изучение структуры и особенностей эмоционально-волевых и когнитивных нарушений у юношей призывного возраста, обратившихся в психоневрологический диспансер в период с 2012 по 2021 годы.

\section{Характеристика выборки и методы исследования}

Нами проводился анализ данных патопсихологического тестирование 146 юношей призывного возраста, направленных медицинскими комиссиями военных комиссариатов в психоневрологический диспансер в период с 2012 по 2021 гг.

Патопсихологическое исследование проводилось по следующей схеме: 1. изучение и психологический анализ данных истории болезни пациента; 2. знакомство с пациентом и ориентировка его в ситуации патопсихологического исследования; 3. выяснение жалоб пациента на состояние когнитивных психических функций и эмоционально-личностной сферы; 4. непосредственное проведение патопсихологического исследования; 5. обработка и интерпретация результатов; 6. написание заключения по данным исследования. 
При проведении патопсихологической диагностики были использованы следующие методики:

1) внимание: «Таблицы Шульте» (автор Вальтер Шульте, предложена к использованию Б.Бурдон) для изучения концентрации и устойчивости внимания и динамики умственной работоспособности;

2) изучение памяти: «Заучивание 10 слов» (А.Р. Лурия) - слуховая механическая; «Пиктограмма» (А.Р. Лурия) - опосредованная зрительная; «Воспроизведение прочитанного рассказа \басни» (А.Р. Лурия) - смысловая.

3) мышление: «Классификация предметов» (модификация Л.Н. Собчик) - исследует нарушение операционального и мотивационного звена мышления; «Исключение предметов» (модификация Н.Л. Белопольской) - выявляет особенности протекания процессов анализа, сравнения и синтеза; «Сравнение понятий» (Л.С. Сахарова - Л.С. Выготского) - выявляет особенности протекания процессов анализа, сравнения и синтеза; «Простые аналогии» (Ю.Л. Глаткова) - изучение способности находить логические связи и отношения между понятиями; «Метафоры и пословицы» (Б.Ф. Зейгарник) - выявляет понимание переносного смысла (процесс абстрагирования), а также целенаправленность суждений; «Пиктограмма» (А.Р. Лурия) исследование ассоциативного компонента мышления;

4) Эмоционально-волевая и личностная сфера: метод наблюдения; метод опроса; стандартизированные личностные опросники (MМРI (модификация Л.Н. Собчик), ПДО (А.Е. Личко), HADS - госпитальная шкала тревоги и депрессии (A.S. Zigmond, R.P. Snaith), SCL-90-R (Derogatis) - выраженность психопатологической симптоматики, опросник суицидального риска «Сигнал» (Зотов М.В., Петрукович В.М., Сысоев В.Н.); проективные тесты (РНЖ (М.З.Дукаревич), тест выбора цвета М. Люшера, - рисунок человека (А.Л.Венгер).

\section{Результаты исследования и их обсуждение}

За период с 2012 по 2021 гг. в психоневрологический диспансер по направлению из военкомата с целью выявления противопоказаний к службе в вооруженных силах было направлено 146 юношей призывного возраста (рис. 1). 


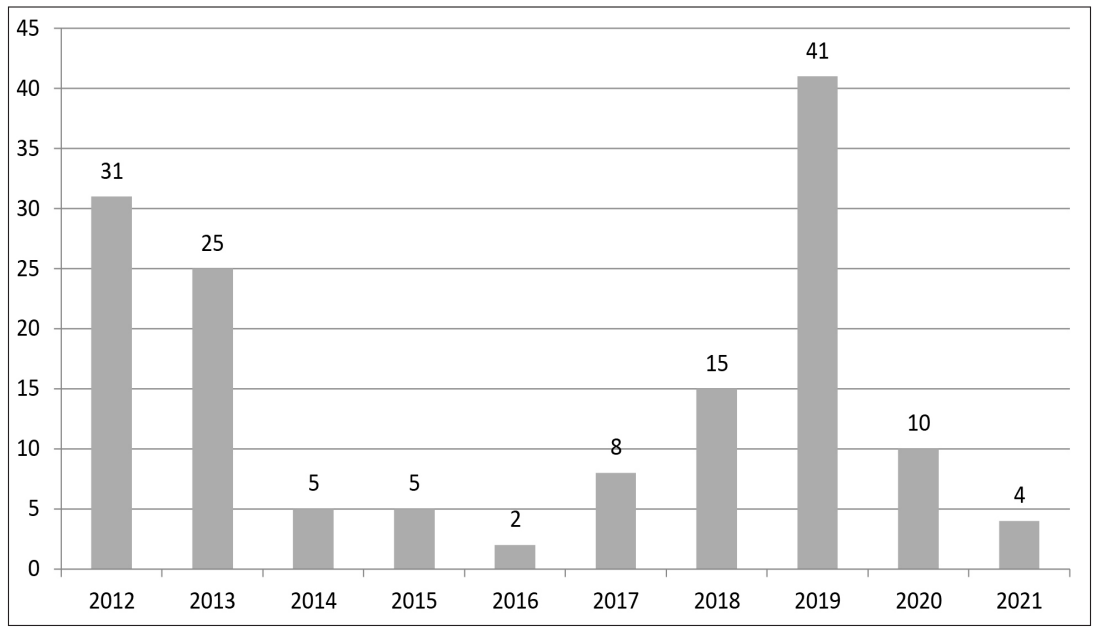

Рис. 1. Динамика обращений юношей призывного возраста в психоневрологический диспансер в период с 2012 по 2021 гг., человек.

Анализ обращений призывников показывает, что максимальное число обратившихся пришлось на 2019 г. - 41 человек $(28,1 \%)$, а минимальное на 2016 г. - 2 человека (1,7\%). У 14 юношей призывного возраста $(9,6 \pm 2,4 \%)$ патология, препятствующая службе в армии, выявлена не была.

По результатам анализа выявленной патологии призывники были объеденены в 6 групп (рис. 2).

Наибольшее число выявленной патологии отнесено в группу акцентуация-транзиторное психотическое расстройство $(39,4 \pm 4,3 \%)$. Второе место занимает группа «шизофрения и шизотипические расстройства» $(20,4 \pm 3,5 \%)$. На третьем месте расположилась патология, объединенная в группу «умственная отсталость» $(16,7 \pm 3,2 \%)$. Четвертое и пятое место разделили «расстройство личности» $(11,4 \pm 2,8 \%)$ и когнитивные нарушения $(9,1 \pm 2,5 \%)$. Реже всего выставлялся диагноз «тревожно-депрессивное расстройство» $(3 \pm 1,5 \%)$. Для каждой группы были выявлены свои психологические особенности, которые необходимо учитывать не только при определении годности к службе, но и определения условий срочной службы. 


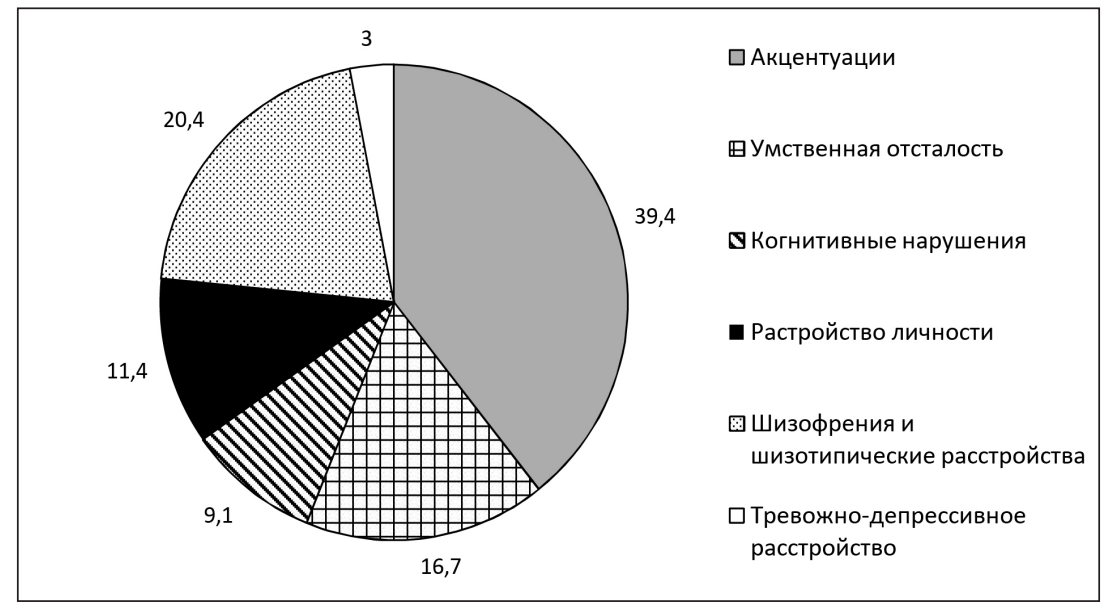

Рис. 2. Структура патологии, выявленной у юношей призывного возраста, обратившихся в психоневрологический диспансер в период с 2012 по 2021 гг., в \%.

За исследуемый период было зафиксировано 52 человека, входящих в группу акцентуация-транзиторных психотических расстройств. Пики по количеству диагнозов наблюдаются в 2013 году - 14 человек (26,92\%), в 2012 году - 12 человек (23,08\%), а также 2019 году - 12 человек $(23,08 \%)$. В 2016 году не выявлено ни одного человека. Среди обследованных и включенных в группу «акцентуация-транзиторное психотическое расстройство» наиболее часто встречались акцентуация по гипертимному типу (30,77\%), акцентуация по лабильному типу $(15,38 \%)$ и акцентуация по эпилептоидному типу $(13,46 \%)$ Значительно реже встречались: акцентуация по неустойчивому типу, акцентуация по шизоидному типу, акцентуация по истероидному типу, акцентуация по циклотимному типу (по $7,69 \%)$, акцентуация по сенситивному типу (3,85\%), акцентуация по экзальтированному типу (3,85\%), акцентуация по возбудимому типу (1,92\%), акцентуация по астено-невротическому типу (1,92\%).

Для обследованных лиц из этой группы были характерны следующие особенности: снижение отсроченной памяти; неустойчивость активного внимания и истощаемость психических процессов; сниже- 
ние способности к абстрагированию; тенденция к снижению процесса обобщения; показатели интеллектуального развития варьируются от среднего к низкому (в нормативном разбросе); в эмоционально-личностной сфере наблюдаются акцентуации характера, а также эмоционально-волевые нарушения; отмечается нанесение самоповреждений.

Призывников, которые были отнесены к группе диагноза «умственная отсталость», выявлено 22 человека. В 2012 году зафиксированное 12 человек (54,55\%). В 2014, 2015, 2016, 2017, 2018, 2021 годах диагноза не поставлено. При этом диагноз «легкая умственная отсталость» был поставлен в 95,5\% случаев, в 4,5\% была определена «интеллектуальная недостаточность».

Для призывников с этой группой диагнозов было характерно: крайне низкий уровень общих сведений и знаний; скудный словарный запас, узкий кругозор; темп работоспособности неравномерный, с тенденцией к снижению к концу исследования; активное внимание с трудностями концентрации и переключения, истощаемость психических процессов; дефицитарность мнестических функций; при исследовании мыслительной деятельности выявляется недостаточность процессов обобщения и абстрагирования, конкретность мышления; уровень интеллекта не соответствует возрасту (в рамках легкой умственной отсталости).

Когнитивные нарушения (на фоне органического поражения ЦНС) были выявлены у 12 призывников. В 2019 году максимальное количество поставленного диагноза - 4 (33,3\%). В 2017, 2021, 2020 годах когнитивных нарушений не было обнаружено. Для обследованных из этой группы было характерно: инструкции к методикам усваивают с 1-2 предъявления, не всегда удерживает их до конца пробы; темп работы неравномерный, с тенденцией к утомлению; объем и концентрация активного внимания с легким снижением, с тенденцией к истощаемости; кратковременная и отсроченная механическая память снижены; при исследовании операциональной сферы мышления выявляется легкое снижение процессов обобщения и абстрагирования; интеллектуальное развитие соответствует низкой норме. 
За исследуемый период у 15 юношей обнаружены расстройства личности. Наибольшее число поставленного диагноза приходится на 2019 год - 5 человек (33,3\%). В 2014, 2015, 2016, 2018 годах юношей с данных расстройством не было установлено. У обследованных в данной группе наиболее часто были установлены параноидное или смешанное расстройство $(26,7 \%)$, истероидное расстройство $(20,0 \%)$ и эмоционально-неустойчивое расстройство (20,0\%). Ананкастное, тревожное расстройство, расстройство личности зависимого типа, нарушения по интровертированному типу, неуточненное расстройство встречались по 6,7\%.

К особенностям, выявленным при обследовании призывников из этой группы, можно отнести: объем и концентрация активного внимания в пределах нормативных границ; в мыслительной сфере отмечается склонность к рассуждательству и субъективизм суждений; исследование памяти не выявило значительных нарушений; в ассоциативном компоненте мышления наблюдаются единичные неадекватные ассоциативные образы; показатели интеллектуальной сферы в большинстве соответствует средней норме; в эмоционально-личностной сферы выявляются нарушения распознавания собственных эмоций и чувств, а также чувств и эмоций других людей; выявляется эмоциональная неустойчивость, тенденция к избеганию ответственности, ирреальность притязаний, черты эмоциональной незрелости, трудности и нарушения социальной адаптации; склонность преувеличивать враждебность отношения к себе других; также встречаются склонность к депрессии, тревоге, обсессивно-компульсивные расстройства, различные самоповреждения, незавершенный суицид или демонстративные суицидальные попытки.

Юношей с диагнозами шизофрения и шизотипические расстройства выявлено 27 человек. Максимальное количество поставленных диагнозов приходится на 2019 год - 12 человек (44,44\%). В 2013, 2014 годах диагнозов не зафиксировано. При этом шизоидное расстройство было выявлено у 77,8\% из них, а шизофрения у 22,2\%. Для обследованных с диагнозом шизоф- 
рения было характерно: неустойчивость активного внимания, легкое снижение смысловой памяти; нарушение ассоциативного и мотивационного компонентов мышления; нарушение целенаправленности мыслительных операций; своеобразие, субъективность, бессодержательность и нелогичность суждений; при исследовании операциональной стороны мышления отмечается искажение процессов обобщении и абстрагирования; неэмоционально-волевые нарушения в виде неадекватности эмоций, своеобразия восприятия, отгороженность;

Для тех, у кого были выявлены шизотипические расстройства характерно: при исследовании мышления могут отмечаться единичная актуализация латентных признаков в процессе обобщения; показатели интеллектуального уровня варьируется от высокой до низкой (в нормативном разбросе); в личностной сфере трудности в установлении межличностных контактов; замкнутость и аутизация, эмоциональная холодность; отмечается снижение уровня социальной активности.

Юношей, с чертами тревожно-депрессивного расстройства за выбранный промежуток времени, выявлено 4 человека, из которых в 2012 году определено 2 человека, 2018 году - 1 человек, 2019 году 1 человек. При этом у 75\% из них было выявлено сенситивное расстройство, а у $25 \%$ - тревога.

Для лиц из этой группы характерно: личностная сфера характеризуются неустойчивостью, избыточной эмоциональной напряженностью, мнительностью, тревожно-депрессивным фоном настроения; высокие значения показателей по шкалам ипохондрии, депрессии, невротизма и тревоги.

\section{Заключение}

По результатам проведенного нами исследования, можно сделать следующие выводы.

1. Проведенный анализ обращений юношей призывного возраста в психоневрологический диспансер за 10 лет установил разнонаправленность динамики выявленной у них патологии. 
2. Ведущими группами выявленной патологии у обследованных призывников являются: акцентуация-транзиторное психотическое расстройство $(39,4 \pm 4,3 \%)$; шизофрения и шизотипические расстройства $(20,4 \pm 3,5 \%)$; умственная отсталость $(16,7 \pm 3,2 \%)$.

3. Для каждой группы были выявлены свои психологические особенности, которые необходимо учитывать не только при определении годности к военной службе, но и определения условий службы.

Своевременное выявление патопсихологических расстройств у лиц призывного возраста позволяет не только предотвратить проблемы, могущие возникнуть во время несения срочной службы, но и начать своевременную коррекционную работу, дающую возможность остановить дальнейшее ухудшение психологического состояния молодых людей.

Область применения результатов. Результаты исследования могут быть использованы в работе патопсихологов и призывных комиссий военкоматов, а также при проведении занятий со студентами специальности «клиническая психология».

Информация о конфликте интересов. Авторы заявляют об отсутствии конфликта интересов.

Информация о спонсорстве. Исследование проведено без финансовой поддержки.

\section{Список литературы}

1. Бохан Н.А., Евсеев В.Д., Мандель А.И. Распространенность психических и наркологических расстройств среди лиц призывного возраста в регионах РФ // Социальная и клиническая психиатрия. 2019. №3. С. 102-108.

2. Шамрей В.К., Евдокимов В.И., Григорьев С.Г., Сиващенко П.П., Лобачев А.В. Обобщенные показатели психических расстройств у личного состава вооруженных сил России (2003-2016 гг.) // Медикобиологические и социально-психологические проблемы безопасности в чрезвычайных ситуациях. 2017. № 2. С. 50-65. 
3. Лисаускене О.В. Динамика клинической картины эмоционально неустойчивого расстройства личности у призывников, признанных негодными или ограниченно годными к несению военной службы по призыву // Социальная и клиническая психиатрия. 2019. № 4. С. 29-34.

4. Герасименко М.В. Психопатия неустойчивого типа [Электронный pecypc]. M., 2019. https://www.krasotaimedicina.ru/diseases/psychiatric/ unstable-psychopathy (обращение 27.09.2021)

5. Яценко, К.О. Эмоционально неустойчивое расстройство личности у военнослужащих по призыву (клинико-динамический аспект): Автореф. дисс. ... канд. мед.наук. Томск, 2014. 28 с.

6. Шведов Е.И., Бравве Ю.И., Бабенко А.И. Бабенко Е.А. Распространенность заболеваний среди лиц, призываемых на военную службу // Проблемы социальной гигиены, здравоохранения и истории медицины. 2016. №5. С. 276-281.

7. Согияйнен А.А. Состояние здоровья военнослужащих по призыву как показатель эффективности профилактических мероприятий во время подготовки граждан к военной службе // Современные проблемы здравоохранения и медицинской статистики. 2019. №1. С. 256-264.

8. Верховцева Т.Н., Ильинский С.В. Особенности психологической готовности к службе призывников сельской и городской местности // Вестник Самарской гуманитарной академии. Серия: Психология. 2019. №1 (25). С. 104-116.

9. Лисаускене О.В. Динамика клинической картины эмоционально неустойчивого расстройства личности у призывников, признанных негодными или ограниченно годными к несению военной службы по призыву // Социальная и клиническая психиатрия. 2019. №4. C. 29-34.

10. Берегова И.Л., Сустретов П.В. Методы социально-психологического изучения граждан, подлежащих призыву на военную службу // Международный журнал гуманитарных и естественных наук. 2016. №1. С. 60-62.

11. Краснов И.В. К вопросу профессионального психологического отбора граждан подлежащих призыву на военную службу в войска 
национальной гвардии Российской Федерации // Современное педагогическое образование. 2021. №6. С. 20-24.

\section{References}

1. Bohan N.A., Evseev V.D., Mandel'A.I. Rasprostranennost' psihicheskih i narkologicheskih rasstrojstv sredi lic prizyvnogo vozrasta v regionah RF [Prevalence of mental and substance use disorders among persons of military age in regions of the Russian Federation]. Social'naja i klinicheskaja psihiatrija [Social and clinical psychiatry], 2019, no. 3, pp. 102-108.

2. Shamrej V.K., Evdokimov V.I., Grigor'ev S.G., Sivashhenko P.P., Lobachev A.V. Obobshhennye pokazateli psihicheskih rasstrojstv u lichnogo sostava vooruzhennyh sil Rossii [Generic indicators for mental disorders in the military personnel of the armed forces of Russia (2003-2016)]. Medikobiologicheskie i social'no-psihologicheskie problemy bezopasnosti v chrezvychajnyh situacijah [Medico-Biological and Socio-Psychological Problems of Safety in Emergency Situations], 2017, no. 2, pp. 50-65.

3. Lisauskene O.V. Dinamika klinicheskoj kartiny jemocional'no neustojchivogo rasstrojstva lichnosti u prizyvnikov, priznannyh negodnymi ili ogranichenno godnymi k neseniju voennoj sluzhby po prizyvu [Dynamics of the clinical picture of emotionally unstable personality disorder in conscripts recognized as unfit or partially fit for conscription]. Social'naja i klinicheskaja psihiatrija [Social and clinical psychiatry], 2019, no. 4, pp. 29-34.

4. Gerasimenko M.V. Psihopatija neustojchivogo tipa [Unstable type of psychopathy]. Moscow, 2019. https://www.krasotaimedicina.ru/diseases/psychiatric/unstable-psychopathy (accessed September 27, 2021)

5. Jacenko, K.O. Jemocional'no neustojchivoe rasstrojstvo lichnosti u voennosluzhashhih po prizyvu (kliniko-dinamicheskij aspekt) [Emotionally unstable personality disorder in conscripted servicemen (clinical and dynamic aspect)]: Avtoref. diss. ... kand. med.nauk. Tomsk, 2014, 28 p.

6. Shvedov E.I., Bravve Yu.I., Babenko A.I. Babenko E.A. Rasprostranennost' zabolevanij sredi lic, prizyvaemyh na voennuyu sluzhbu [The prevalence of diseases among persons drafted to military service]. Problemy social'noj gigieny, zdravoohraneniya i istorii mediciny [The problems 
of social hygiene, public health and history of medicine], 2016, no. 5, pp. 276-281.

7. Sogiyajnen A.A. Sostoyanie zdorov'ya voennosluzhashchih po prizyvu kak pokazatel' effektivnosti profilakticheskih meropriyatij vo vremya podgotovki grazhdan $\mathrm{k}$ voennoj sluzhbe [The health condition of military servants at the call as a indicator of the efficiency of prevention measures during preparation of citizens for military service]. Sovremennye problemy zdravoohraneniya i medicinskoj statistiki [Current problems of health care and medical statistics], 2019, no. 1, pp. 256-264.

8. Verkhovtseva T.N., Ilyinsky S.V. Osobennosti psihologicheskoj gotovnosti k sluzhbe prizyvnikov sel'skoj i gorodskoj mestnosti [Features of psychological readiness for service of recruits of rural and urban areas]. Vestnik Samarskoj gumanitarnoj akademii. Seriya: Psihologiya [The Bulletin of the Samara Humanitarian Academy. A series Psychology], 2019, no. 1 (25), pp. 104-116.

9. Lisauskene O.V. Dinamika klinicheskoj kartiny emocional'no neustojchivogo rasstrojstva lichnosti u prizyvnikov, priznannyh negodnymi ili ogranichenno godnymi k neseniyu voennoj sluzhby po prizyvu [Dynamics of the clinical picture of borderline personality disorder in conscripts recognized as unfit or limited fit for military service]. Social'naya $i$ klinicheskaya psihiatriya [Social and clinical psychiatry], 2019, no. 4, pp. 29-34.

10. Beregova I.L., Sustretov P.V. Metody social'no-psihologicheskogo izucheniya grazhdan, podlezhashchih prizyvu na voennuyu sluzhbu [Methods of socio-psychological study of citizens be called up for military service]. Mezhdunarodnyj zhurnal gumanitarnyh i estestvennyh nauk [International Journal of Humanities and Natural Sciences], 2016, no. 1 , pp. 60-62.

11. Krasnov I.V. K voprosu professional'nogo psihologicheskogo otbora grazhdan podlezhashchih prizyvu na voennuyu sluzhbu v vojska nacional'noj gvardii Rossijskoj Federacii [On the issue of professional psychological selection of citizens subject to conscription for military service in the national guard of the Russian Federation]. Sovremennoe pedagogicheskoe obrazovanie [Modern Pedagogical Education], 2021, no. 6, pp. 20-24. 


\section{ДАННЫЕ ОБ АВТОРАХ}

Сенченко Галина Васильевна, преподаватель кафедры клинической психологии и психотерапии с курсом ПО ФГБОУ ВО «Красноярский государственный медицинский университет имени профессора В.Ф. Войно-Ясенецкого» Министерства здравоохранения Российской Федерации ул. Партизана Железняка, 1, г. Красноярск, Красноярский край, 660022, Российская Федерация senchenkogalina@yandex.ru

Сенченко Алексей Юрьевич, доцент кафедры управления и экономики здравоохранения ИПО, кандидат медицинских наук, доцент

ФГБОУ ВО «Красноярский государственный медицинский университет имени профессора В.Ф. Войно-Ясенецкого» Министерства здравоохранения Российской Федераџии ул. Партизана Железняка, 1, г. Красноярск, 660022, Российская Федерация sentchenko@mail.ru

Саури Виктория Владимировна, медицинский психолог КГБУЗ «Красноярский краевой психоневрологический диспансер № 1»

ул. Курчатова, 14, г. Красноярск, 660041, Российская Федерациия vikasauri78@mail.ru

Серебренникова Полина Михайловна, студент медико-психолого-фармацевтического факультета (клиническая психология) ФГБОУ ВО «Красноярский государственный медицинский университет имени профессора В.Ф. Войно-Ясенецкого» Министерства здравоохранения Российской Федерации ул. Партизана Железняка, 1, г. Красноярск, 660022, Российская Федерация polina_serebrenikova@mail.ru 


\section{DATA ABOUT THE AUTHORS}

Galina V. Senchenko, Teacher of the Department of Clinical Psychology and Psychotherapy

Krasnoyarsk State Medical University named after Professor V.F. Voino-Yasenetsky

1, Partizan Zheleznyak Str., Krasnoyarsk, 660022, Russian Federation

senchenkogalina@yandex.ru

SPIN-code: 9967-7933

ORCID: 0000-0002-1920-0710

ResearcherID: AAO-2210-2020

Alexey Yu. Senchenko, Associate Professor of the Department of Management and Economics of Healthcare, Ph.D. in Medicine Krasnoyarsk State Medical University named after Professor V.F. Voino-Yasenetsky

1, Partizan Zheleznyak Str., Krasnoyarsk, 660022, Russian Federation

sentchenko@mail.ru

SPIN-code: 9794-7985

ORCID: 0000-0002-0190-5800

ResearcherID: N-7426-2015

Victoria V. Sauri, medical psychologist

Krasnoyarsk Regional Psychoneurological Dispensary No. 1 14, Kurchatov Str., Krasnoyarsk, 660041, Russian Federation vikasauri78@mail.ru

Polina M. Serebrennikova, student of the Faculty of medicine, psychology and pharmacy (clinical psychology)

Krasnoyarsk State Medical University named after Professor V.F. Voino-Yasenetsky

1, Partizan Zheleznyak Str., Krasnoyarsk, 660022, Russian Federation polina_serebrenikova@mail.ru 